University of Nebraska - Lincoln

DigitalCommons@University of Nebraska - Lincoln

Faculty Publications, Department of Psychology

Psychology, Department of

3-8-2004

\title{
Gender Socialization in Latino/a Families: Results from Two Retrospective Studies
}

\author{
Marcela Raffaelli \\ University of Nebraska-Lincoln, mraffaelli1@unl.edu \\ Lenna L. Ontai \\ University of California - Davis, lontai@ucdavis.edu
}

Follow this and additional works at: https://digitalcommons.unl.edu/psychfacpub

Part of the Psychiatry and Psychology Commons

Raffaelli, Marcela and Ontai, Lenna L., "Gender Socialization in Latino/a Families: Results from Two Retrospective Studies" (2004). Faculty Publications, Department of Psychology. 61.

https://digitalcommons.unl.edu/psychfacpub/61

This Article is brought to you for free and open access by the Psychology, Department of at DigitalCommons@University of Nebraska - Lincoln. It has been accepted for inclusion in Faculty Publications, Department of Psychology by an authorized administrator of DigitalCommons@University of Nebraska - Lincoln. 


\title{
Gender Socialization in Latino/a Families: Results from Two Retrospective Studies
}

\author{
Marcela Raffaelli \\ Department of Psychology and Institute for Ethnic Studies, University of Nebraska - Lincoln \\ Corresponsing author, e-mail: mraffaelli1@unl.edu \\ Lenna L. Ontai \\ Department of Human and Community Development, University of California - Davis
}

\begin{abstract}
In this article, we present findings from 2 studies designed to explore gender-related socialization in Latino/a families. In Study 1, 22 adult Latinas (ages 20-45) completed in-depth interviews. In Study 2, 166 Latino/a college students (58\% women; $M$ age 21.4 years) completed self-report surveys. Study 1 findings suggest that many Latino/a parents socialize their daughters in ways that are marked by "traditional" genderrelated expectations and messages. Results of Study 2, which included descriptive analyses and the creation of scales to explore family correlates of gender-related socialization, support and expand these findings. Male and female respondents described different experiences of household activities, socialization of gender-typed behavior, and freedom to pursue social activities or gain access to privileges. Parental characteristics, particularly gender role attitudes, were linked to gender-related socialization. Findings are discussed in light of the developmental and cultural literature on gender-related socialization.
\end{abstract}

Key words: Latino/a families, gender socialization, parenting

In most societies, biological sex provides an organizing framework for how individuals are treated and how they are expected to behave (Rossi, 1985; Williams \& Best, 1994). The process of gender socialization has been described by developmental scholars (for reviews, see Huston, 1983; Ruble \& Martin, 1998), and an extensive body of literature suggests that parents play a key role in gender socialization. Despite dramatic changes in gender roles that have occurred in the United States during recent decades, parents continue to engage in differential socialization regarding gender expectations (Huston \& Alvarez, 1990). A meta-analysis of differential parental socialization in eight domains (e.g., achievement, punishment, nurturance) revealed significant - albeit modest - sex differences in only one area: encouragement of gender-typed activities and perceptions of gender-stereotyped characteristics (Lytton \& Romney, 1991). Theorists have proposed that during adolescence there is an intensification of gender-related socialization (Hill \&
Lynch, 1983). Empirical studies have shown that adolescent gender intensification does occur (Ruble \& Martin, 1998), particularly when parents hold traditional views regarding gender (Arnett, 2001).

One major limitation of research on gender socialization is its lack of attention to ethnic differences. To date, most U.S.-based studies of normative development have involved primarily European American samples (McDade, 1995), and this is true of research on gender socialization. For example, Ruble and Martin's chapter on gender development in the latest Handbook of Child Psychology (Ruble \& Martin, 1998) discusses the social construction of gender, but does not address issues of ethnicity or culture related to gender development. In Lytton and Romney's meta-analysis (Lytton \& Romney, 1991), ethnicity was coded but not included in the analyses, and the sample descriptions do not mention ethnicity. As the U.S. population becomes increasingly heterogeneous, information about how culturally diverse 
families raise their children is needed to inform theorists, researchers, and practitioners (Parke \& Buriel, 1998). In this article, we focus on gender socialization among Latinos/as, defined as individuals of Mexican, Puerto Rican, Cuban, or other Central and South American origin or descent (Day, 1996).

This focus is warranted given the general lack of information about Latino/a families (McLoyd, Cauce, Takeuchi, \& Wilson, 2000) and the fact that by the year 2050, nearly one-third of the under-age-19 population in the United States will be Latino/a (U.S. Department of Health and Human Services, 2001). Although the diversity within this population makes it unwise to generalize too broadly about group beliefs and practices, scholars have identified a set of cultural values that are relevant to gender-related socialization in Latino/a families. One value is familismo, an emphasis on family relationships and a strong value placed on childbearing as an integral part of family life and the feminine gender role (Flores, Eyre, \& Millstein, 1998). Another value is respeto, which refers to an emphasis on respect and hierarchy in social relationships (Parke \& Buriel, 1998). Finally, traditional Latin cultures are marked by strong gender role divisions. The idealized traditional feminine gender role involves being submissive, chaste, and dependent, whereas the masculine gender role involves being dominant, virile, and independent (Comas-Diaz, 1987). Some scholars have criticized this depiction of traditional gender roles as stereotypical and invalid (e.g., Amaro, 1988; Singer et al., 1990); however, there is empirical support for the notion that traditional values regulate the sexual behavior of many Latinos/as. For example, among Mexican American adolescents, partner preferences reflect the cultural values of respeto and familismo as well as traditional hierarchical gender roles (Flores et al., 1998; see also Raffaelli \& Suarez-al-Adam, 1998).

There is a rich body of theoretical and anecdotal literature on gender-related socialization in Latino/a families, which is often discussed in the context of therapeutic issues (Espin, 1984/1997) or sexuality and HIV/AIDS (Marin \& Gomez, 1997). Because the identification of broad-based cultural values does not provide information about how families typically behave in their daily lives (Valenzuela, 1993), it is important to move to the next step and examine actual socialization practices. To date, only a small number of studies have examined how Latino/a families "translate" culturally based beliefs about gender into specific parenting practices. Several scholars have noted that boys and girls are socialized differently, particularly concerning sexuality (Comas-Diaz, 1987; Reid, Haritos, Kelly, \& Holland, 1995). In focus groups with Puerto Rican and Mexican adolescent girls and their mothers, family beliefs regarding the importance of maintaining teenaged daughters' virginity were linked to the establishment of rules regarding dating and contact with boys; sons did not have similar limitations (Villaruel, 1998). An exploratory study of family of origin experiences revealed that many Latinas were discouraged from becoming romantically involved while living at home and that parents limited adolescent daughters' contacts with potential romantic partners (Raffaelli \& Ontai, 2001). In another study, Latina and Portuguese adolescent girls said that "their parents are too strict, treat their daughters differently than sons, and are 'too concerned' about their safety" (Taylor, 1996, p. 128). Other researchers have described how a cultural emphasis on women's innocence may make Latino/a parents reluctant to discuss sexuality with daughters (Darabi \& Ascencio, 1987; Marin \& Gomez, 1997). Much of the research has focused on the experiences of girls; however, one comparative study revealed that Latina adolescents reported stricter rules about dating and sex, and more conservative maternal expectations regarding sexuality, than did their male counterparts (Hovell et al., 1994).

These studies suggest that cultural beliefs regarding appropriate gender-related behavior affect how Latino/a families attempt to regulate their adolescent children's sexual involvement. However, few studies have focused on the more basic question of how Latino/a parents attempt to teach their children what it means to be a woman or a man. Thus, the first goal of the current analysis was to examine parenting practices specifically linked to gender-related socialization. Another issue is that Latino/a culture is not homogeneous; therefore, a second goal was to identify factors linked to within-group differences in gender-related socialization, including demographic and attitudinal factors. The analysis draws on data from a larger program of research in which adults were asked to report retrospectively on their experiences while growing up. The research was conducted in two phases: a small-scale exploratory study involving in-depth interviews was followed by a larger survey study. 


\section{STUDY 1}

\section{Method}

\section{Participants and Procedures}

This study drew on an opportunity sample of women who responded to recruitment materials that targeted 20-to 45-year-old Latina/Hispanic women who had grown up in Spanish-speaking families but had lived in the United States for at least 8 years. Inclusion criteria stemmed from the overall goal of the study, which was to understand family factors that might enhance or mitigate sexual risk-taking among highly acculturated Latinas. Given the original focus on women, it was not until the second phase that men were included in the research. Various recruitment methods were used, including direct mailings to Latina faculty and staff at a large mid-western university, postings of informational flyers in public locations, and participant referrals. After providing informed consent, women took part in individual interviews conducted in English by the first author. Participants received $\$ 20$ to cover their time and transportation costs.

Twenty-two women had complete data and were included in the analyses (two participants were excluded because of equipment problems that resulted in inaudible tapes). The average age of the sample was 31.2 years (median 27 years; range 20-45). Two-fifths (41\%) of the respondents had never been married, $41 \%$ were currently married, and $18 \%$ were separated or divorced. Over two-thirds $(68 \%)$ were Catholic; the remainder reported other $(23 \%)$ or no (9\%) religious affiliations. All of the respondents had graduated from high school; $32 \%$ had attended college but had not graduated; $18 \%$ had graduated; and $18 \%$ had some graduate education. In contrast, parental levels of education were lower: over one-half of the respondents' fathers (57\%) and mothers (55\%) had not graduated from high school, and the majority of these parents left school by the ninth grade. A number of parents had graduated from high school (14\% of fathers and $23 \%$ of mothers) or attended/graduated from college (29\% of fathers and $23 \%$ of mothers).

Consistent with the study's inclusion criteria, participants were highly acculturated on the basis of language and birthplace. Current language use was assessed using a modified version of the Marin short acculturation scale (G. Marin, Sabogal, B. V. Marin, Otero-Sabogal, \& Perez-Stable, 1987). Participants in- dicated which language they typically think in and use with partners, friends, and at work on a 3-point scale $(1=$ mostly or only Spanish, 2 = both equally, $3=$ mostly or only English). Responses to the four items were averaged, and the resulting scale indicated high levels of acculturation in the sample $(M=2.59, \mathrm{SD}=$ $0.51)$. The majority of the 22 respondents $(n=19)$ had been born in the United States. One-half of the women had at least one parent born outside the United States; the others had two United States-born parents. Only three of the respondents had two or more U.S.-born grandparents. Most respondents $(\mathrm{n}=16 ; 73 \%)$ were of Mexican origin or descent, and the remainder were from other Latin American or Caribbean countries.

\section{Measures}

The interview guide consisted of open-ended and structured questions that dealt with three overarching topic areas: sexual socialization within the family of origin; early romantic and sexual experiences; and sexuality-related beliefs, attitudes, and behavior. A number of the sexual socialization questions dealt with gender role socialization (e.g., How did your parents teach you about how girls and boys "should" behave? Do you remember any specific examples? Did your parents ever get angry or upset when you didn't behave in a certain way?). These questions formed the basis for the current analysis.

At the start of the interview, the first author discussed with each respondent how the project fit into the larger research program and emphasized its exploratory nature. Respondents were told that their role was not simply to provide answers but to help figure out what the questions were; that is, they were treated as co-participants in the research process, and enlisted as collaborators in making meaning of their experiences. Thus, although the interview protocol was used as a guide and all women were asked the same core set of questions, not all questions were asked in the same order and some interviews covered additional areas. Interviews averaged 60-90 min, and all were audiotaped.

\section{Data Coding and Analysis}

The interviews were professionally transcribed, checked for accuracy by research assistants, and corrected as necessary. This procedure yielded over 400 pages of interview transcripts that were coded in sev- 
eral stages. First, each transcript was reviewed by two independent coders to locate specific segments that dealt with the focal domains addressed in the interview guide. Additional emergent themes were also identified during this process. Coders compared notes, identified discrepancies, and resolved them by discussion. These segments were marked in a qualitative data analysis program (QSR NUD•IST), and the relevant portions of the interviews were extracted and reviewed by two coders to identify emergent themes within each of the focal domains. These themes were coded in the data analysis program, patterns of responses were examined, and "typical" quotes were identified (all participants were assigned pseudonyms to maintain confidentiality).

\section{Results}

Analysis of interview transcripts revealed three overarching themes related to gender socialization: differential treatment of girls and boys, enforcement of stereotypically feminine behavior among daughters, and curtailment of girls' activities outside the home.

\section{Differential Treatment of Girls and Boys}

Gender role differentiation and privileging of boys in families with both sons and daughters were frequent themes among the women who participated in Study 1. For example, sons were typically granted more freedom than daughters. One woman described how she and her brother (1 year older) were treated by their mother:

He had a very much later curfew than I did. He got a car, got to drive a car and then he also got his own car and I never did ...I could only go to school-related activities and he could do about anything, he could go any place he wanted and so I always felt like I was the one that she just didn't ever let go, she always kept control over everything that I did.... (Gloria, age 41)

Daughters and sons tended to have different household responsibilities; in particular, girls were expected to help around the house, whereas boys were not:

Well my brothers were able to do a lot more than us [girls] ...we had to make sure all the housework was done before we even went to school ...we had the responsibility of the housework and taking care of the younger kids and whatever and the boys didn't have to worry about that, they didn't have to wor- ry about cleaning, they didn't have to worry about anything like that, they could do pretty much what they wanted just as long as they were back at home by a certain hour or whatever. (Olivia, age 25)

\section{Enforcement of Stereotypically Feminine Behavior}

A number of respondents said that their parents encouraged them to act in "feminine" ways. For example, when asked how her parents taught her about appropriate feminine behavior, one young woman reported:

Girls are always supposed to be proper and they weren't supposed to do guy things. You know, like we were never allowed to have guns, play guns or stuff like that. We never got a Ken doll. I don't know why, but we never did. We'd always ask for one, but never got one. I don't know. Girls were supposed to have dresses, you know, and stuff like that. Wear always like perfect little matching earrings, you know, and dresses and little outfits, little like all girl-type things. (Estrela, age 22)

Another woman recalled how she felt when she did not receive the toys she desired:

\begin{abstract}
Ah, my, I always was envious of my brother, especially when we were young, I was a tomboy when I was a little girl ...he got a bike and I didn't get the bike. He would get, this is a thing when I was a kid I remember this vividly, it just floored me, he got the bright yellow Tonka truck, dump truck and the fire truck and I didn't get, and I loved that stuff .... and of course since he was the only male, I knew since he was the only male he could get whatever he wanted. (Letitia, age 27)
\end{abstract}

Although some degree of "tomboy" behavior was accepted in a number of families, as girls grew older parents tended to become less accepting of "unfeminine" behavior. One young woman described how her first menstrual period marked an abrupt change from the relative freedom of childhood. Her father brought her flowers, and told her:

..."you're a woman now, you're a woman now," and I was just like, I don't want to be one ...I don't want any of this, because it seemed like after that he was going to the store and buying all these things, that now all these different things were going to have to happen and things were really going to have to change, like right after that it was like I was always pushed more to grow out the hair and pushed more to do things that, I kind of lost my freedom .... Freedom to wear what you want to wear and do what you want to do was kind of like shortened .... [My dad got even stricter, cause he was like, well, damn it, you know, this is what, it was almost like this is what he was waiting for, like this, this was it, you know, we'll let you go and do whatever you want until you get this and then once you start your period that's it, boy, it's all over.... (Isabel, age 20) 
Another young woman described her father's belated attempt to inculcate the traditional feminine skill of making tortillas from scratch:

\begin{abstract}
...I wasn't very good, my older sisters were pretty much the ones that did it when my mom was alive, but my dad he was like "you're going to make the tortillas" and I went ahead and made them and he was just getting mad at me, because I wasn't making them round, and I was just like ...I hope this goes over real quick here, but I mean it was just such a funny thing, because, ah, to him what, ah, it's almost like there are traditional roles for females. He wanted the best for us, he wants the best education for us and everything and the best opportunities, but women still need to have their traditional roles of being able to cook, being able to clean, being able to look nice, ah, nicely dressed, ah, and yet not going out with boyfriends before they're married or bringing a man home before, you know, this whole, this whole socialization process is going in my home.... (Rosita, age 26)
\end{abstract}

\section{Curtailment of Girls'Activities}

As these quotes illustrate, many respondents described parental socialization marked by different behavioral expectations for sons and daughters and encouragement of stereotypically feminine behavior in daughters. Running through these remarks is a third theme concerning freedom (or lack of freedom). One young woman vividly described feeling as if she lived in a "little circle" delineated by her parents:

...I kept wanting to go outside of that circle, it was like when I was little I could only go outside to my yard and then, you know, once I got older I could only go to school and back and, you know, once I got like in high school I could only go to the movie theater that was by the house and I wanted to go to the movie theater ...that everyone went to, which was on the other side of town ...[If we went to other people's houses, you know, I could never, I could never say that ...I had to be someplace public and so I would be, forever be lying ...I always had to say, you know, I was out public, we were at the malls, we were at the movies, we were at the library, we were at so and so. (Silvia, age 21)

These results suggest that many children growing up in Latino/a families in the United States experience gender socialization that is marked by traditional expectations and messages. However, because this was a small-scale exploratory study that included only women, it is impossible either to draw conclusions about how common these socialization patterns are or to examine correlates of different socialization patterns. Therefore, the qualitative findings were used to create structured measures of different aspects of family experiences that were included in a survey administered in a second study.

\section{STUDY 2}

\section{Method}

\section{Participants and Procedures}

The target population for Study 2 consisted of all 19-to 45-year-old Latino/a students at four midwestern postsecondary institutions (two state universities, one community college, and one private university). With the cooperation of each institution's registration office, survey packets and subsequent reminder postcards were sent to all currently enrolled students identified as "Latino/Hispanic" in registration records. Depending on the institution, respondents either were paid $\$ 15$ or received $\$ 10$ and were entered into a drawing for an additional bonus payment (compensation was determined in consultation with officials at each institution). To protect students' privacy, survey packets were direct-mailed by each institution and the investigators did not have access to identifying or demographic information. At three institutions it was not possible to restrict the mailing to students in the target age range so the mailing was sent to all Latino/a students, and students were instructed to discard the survey if they were under age 19 (under state law they are considered minors) or over age 45 . Thus, the exact number of students who were eligible to participate is unknown. Eight hundred seventy-one surveys were mailed; 26 were undeliverable or recipients informed the first author that they were ineligible. Two hundred forty-two $(28.6 \%)$ of the remaining 845 surveys were returned. To limit sample heterogeneity and retrospective recall bias, the current analysis was limited to respondents aged 25 and under $(n=166$; $69 \%$ of the sample).

The analysis sample included 97 women and 69 men (median age 21 years). Most were unmarried ( $n$ $=153 ; 92 \%)$ and reported their religious affiliation as Catholic $(n=118 ; 71 \%)$. In terms of generation of immigration, $16 \%$ of the respondents had been born outside the United States (first generation), 29\% were second generation (i.e., the respondent was born in United States but one or both parents were born out- 
Table I. Gender Differences in Parental Enccuragement of Gender-Related Behavior while Respondent Was Growing Up

\begin{tabular}{|c|c|c|c|c|c|c|}
\hline & \multicolumn{2}{|c|}{ Women $(n-97)$} & \multicolumn{2}{|c|}{ Men $(n-69)$} & \multicolumn{2}{|c|}{ Gender diferences } \\
\hline & Mothers & Fathers & Mothers & Fathers & Mothers & Fathers \\
\hline Do outdoor chores & $3.31(1.43)$ & $3.15(1.49)$ & $4.07(1.12)$ & $4.01(1.35)$ & wate & is \\
\hline Play with girls' toys & $3.33(1.33)$ & $2.90(1.36)^{6 t}$ & $1.42(0.93)$ & $1.10(0.52)^{\mathrm{a}}$ & wate & at \\
\hline Play indoors (vs cutdoors) & $1.99(1.33)$ & $1.97(1.31)$ & $1.91(1.15)$ & $1.60(0.98)^{\mathrm{a}}$ & $n s$ & *k \\
\hline Play with boys' toys & $1.79(0.97)$ & $1.85(1.07)$ & $3.32(1.27)$ & $3.50(1.35)$ & sete & at \\
\hline Do indoor chores & $3.80(1.20)$ & $3.30(1.42)^{6 t k}$ & $3.36(1.31)$ & $2.84(1.45)^{6 t}$ & $\star$ & 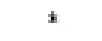 \\
\hline Wear hair long & $2.94(1.61)$ & $2.93(1.69)$ & $1.36(0.82)$ & $1.24(0.77)$ & side & at \\
\hline Take care of younger siblings & $3.36(1.61)$ & $3.21(1.61)$ & $3.20(1.55)$ & $2.83(1.61)$ & ns & ns \\
\hline \multicolumn{7}{|l|}{ Women only } \\
\hline Gender appropriate clothes & $2.59(1.44)$ & $2.25(1.42)^{i k}$ & & & & \\
\hline Be a "tanboy" & $1.60(0.91)$ & $1.81(1.15)^{4 k}$ & & & & \\
\hline Be ladylike & $3.51(1.32)$ & $3.12(1.45)^{\mathrm{at} t}$ & & & & \\
\hline \multicolumn{7}{|l|}{ Men only } \\
\hline Engage in boys activities & & & $3.34(1.32)$ & $3.75(1.39)^{60}$ & & \\
\hline Express feelings & & & $3.03(1.39)$ & $2.24(1.19)^{6 i}$ & & \\
\hline Be "manly"/"macho" & & & $2.57(1.30)$ & $3.03(1.46)^{6 t}$ & & \\
\hline
\end{tabular}

side the United States), 33\% were third generation (i.e., the respondent and both parents were born in the United States but two or fewer grandparents were U.S.-born), and $22 \%$ were fourth generation (i.e., the respondent, both parents, and at least three grandparents were born in the United States). When asked to select the ethnic term(s) that best described them, $39 \%(n=65)$ chose "Hispanic/Latino," 34\% $(n=57)$ chose "Mexican American," and the remainder selected "Mexican" ( $8 \% ; n=13)$, "Puerto Rican" $(4 \% ; n=$ 7), or another term (e.g., "Chicano," "Cuban"; 14\%; $n=24)$.

\section{Measures}

Participants completed structured measures of gender role socialization, differential treatment of sons and daughters, parental gender role attitudes, family language use, and family background characteristics.

To measure gender role socialization, 10 items were derived from a content analysis of the Study 1 interviews. These items assessed how much each parent had encouraged specific behaviors traditionally considered "masculine" or "feminine" while the respondent was growing up. Responses were on a 5point scale $(1=$ not at all, $3=$ somewhat, $5=$ very much). Items and means are presented in Table I; results of factor analyses and scale creation are described in the preliminary results section.

To assess differential treatment of daughters and sons, participants rated the extent to which they and their cross-sex siblings (or relatives if they had no siblings) had similar or different limits placed on them by their parents while they were growing up in 10 different areas identified from a content analysis of Study 1 transcripts. Items were rated on a 5-point scale $(1=$ relatives/siblings had more limits, $3=$ about the same, $5=$ I had more limits). See Table II for itemsand means; results of factor analyses and scale creation are presented in the preliminary results section.

Parental gender roles attitudes were assessed with an adapted version of the USCS Attitudes Toward Gender Scale (Leaper, 1993). Unlike the orig

Table IL Differential Treatment in Comparison to Other-Sex Relatives During Teen Years

\begin{tabular}{|c|c|c|}
\hline & Women $(n-97)$ & Men $(n-69)$ \\
\hline $\begin{array}{l}\text { How late you could stay } \\
\text { out on school nights }\end{array}$ & $3.54(1.32)$ & $2.71(1.28)^{6 t k}$ \\
\hline $\begin{array}{l}\text { How late you could stay } \\
\text { out on weekends }\end{array}$ & $3.65(1.24)$ & $2.78(1.37)^{6 k}$ \\
\hline $\begin{array}{l}\text { Where you could go after } \\
\text { school }\end{array}$ & $3.44(1.12)$ & $2.84(1.18)^{d t}$ \\
\hline $\begin{array}{l}\text { Involvement in after- } \\
\text { school activities }\end{array}$ & $3.14(0.84)$ & $2.82(1.13)^{i}$ \\
\hline $\begin{array}{l}\text { When you could start } \\
\text { dating }\end{array}$ & $3.46(1.24)$ & $2.81(1.01)^{6 t k}$ \\
\hline $\begin{array}{l}\text { With whom you were allowed } \\
\text { to interact }\end{array}$ & $3.27(0.98)$ & $2.91(0.81)^{k}$ \\
\hline $\begin{array}{l}\text { Being alone with a member } \\
\text { of the cther sex }\end{array}$ & $3.68(1.17)$ & $2.72(1.09)^{26 t}$ \\
\hline $\begin{array}{l}\text { Getting a license and } \\
\text { learning to drive }\end{array}$ & $3.38(0.93)$ & $2.90(0.95)^{d t}$ \\
\hline Getting a job & $3.39(1.01)$ & $2.94(0.93)^{k t}$ \\
\hline $\begin{array}{l}\text { Having friends of the } \\
\text { other sex }\end{array}$ & $3.39(0.89)$ & $2.88(0.82)^{i k i}$ \\
\hline
\end{tabular}

Note Response scale: 1 - relative had more limits; 5 - I had more Limats. Pattern of results was replicated with subset of participants with other-sex sibling in same housebold while growing up. ${ }^{*} p<.05 .{ }^{*} p<.01 .{ }^{* k} p<.001$. 
inal self-report scale, respondents were asked how well each of 24 items described each parent's attitudes while they were growing up (e.g., "It is all right for a teenage girl to ask a boy out on a date"). Items were rated on a 5 point scale $(1=$ strongly disagree, 5 $=$ strongly agree). An overall score was computed for each parent such that a higher score indicated more egalitarian gender beliefs (mother $\alpha=.90, M=3.5$, $S D=0.72$; father $\alpha=.92, M=3.1, S D=0.87$ ).

Language use in the family of origin was used to assess acculturation. Parental language use with each other and respondent language use with mother, father, brothers/sisters, and other relatives was assessed on a 5-point scale ( $1=$ English only, $3=$ Both, 5 = Spanish only). Parental language use with each other was kept separate $(M=3.60, S \mathrm{D}=1.72)$, and a family language use scale was computed by averaging across the other four items $(\alpha=.95 ; M=2.94$, $S D=1.63$ ).

Two aspects of family background were assessed. In addition to the United States, parental birthplace included Mexico (12\% mothers and 16\% fathers), South America (15\% mothers and 16\% fathers), Central America (3\% mothers and 4\% fathers), and other (4\% mothers and 3\% fathers). Preliminary analyses of mean differences in parenting variables revealed few differences due to region of birth; thus, parental birthplace was coded as 1 (U.S.; $66 \%$ mothers and $61 \%$ fathers) or 0 (non-U.S.; $34 \%$ mothers and $39 \%$ fathers). Average number of years of education completed was 12.8 for mothers (range 2-17) and 13.0 for fathers (range 0-17). Twelve percent of mothers and fathers had not graduated from high school, $36 \%$ of mothers and $35 \%$ of fathers had graduated or had a GED, and $52 \%$ of mothers and fathers had attended or graduated from college.

\section{Results}

\section{Gender Role Socialization: Descriptive Analyses and Scale Creation}

Young women and men reported differential socialization regarding household activities and social interactions (Table I). Qualitative findings from Study 1 were confirmed. Young women were more likely than young men to say they were encouraged as children to play with girls' toys, do indoor chores, and wear their hair long. Young men reported higher levels of encouragement to play with boys' toys and do outdoor chores. No gender differences emerged on items that assessed encouragement to play indoors or take care of younger siblings. Comparisons of parental behavior within gender revealed that the samesex parent tended to engage in more socialization of traditionally gender-appropriate behavior than the cross-sex parent. That is, mothers were more likely than fathers to encourage stereotypically feminine behaviors in daughters, and fathers were more likely than mothers to encourage stereotypically masculine behaviors in sons.

The 10 items were entered separately for men and women into principal components factor analyses with varimax rotation (factor loadings and statistics are presented in Table III; similar results were obtained with oblimin rotation). For factors with eigenvalues greater than 1.0, scales were computed by averaging across the relevant items. Among the women, three scales emerged for mothers: femininity (5item $\alpha=.73$ ), chores ( 2 items), and tomboy (2 items), and two scales emerged for fathers: femininity (5-item $\alpha=.77$ ) and chores (3-item $\alpha=.42)$. Among the men, two scales emerged for mothers: manliness (3-item $\alpha$ $=.64)$ and sensitivity (3-item $\alpha=.52)$ and three scales emerged for fathers: manliness (3-item $\alpha=.67$ ), sensitivity ( 2 items), and chores (4-item $\alpha=.65$ ). Means and standard deviations for the scales are presented at the bottom of Table III.

\section{Differential Treatment: Descriptive Analyses and Scale Creation}

Qualitative findings were again confirmed. Table II shows results for differential treatment in comparison to cross-sex relatives while growing up (results for siblings were similar). For all 10 items, young women said that they had had more limits placed on them by their parents than their male relatives did, and young men said that they had had fewer limits placed on them than their female relatives did.

The 10 items were entered separately for men and women into principal components factor analyses with varimax rotation (factor loadings and statistics presented in Table IV; similar results were obtained with oblimin rotation). For both young women and men, two factors emerged: social activities (eigenvalue for women $=4.30$; for men $=3.71$ ) and privileges $($ eigenvalue for women $=1.68$; for $\operatorname{men}=2.97$ ). 
Table IIL Factor Loadings and Descriptive Statistics for Gender Rde Socialization Factors

\begin{tabular}{|c|c|c|c|c|c|c|c|c|c|c|}
\hline & \multicolumn{5}{|c|}{ Women $(n-97)$} & \multicolumn{5}{|c|}{ Men $(n-69)$} \\
\hline & \multicolumn{3}{|c|}{ Mothers } & \multicolumn{2}{|c|}{ Fathers } & \multicolumn{2}{|c|}{ Mothers } & \multicolumn{3}{|c|}{ Fathers } \\
\hline & Femininity & Chores & Tomboy & Femininity & Chores & Manly & Sensitive & Manly & Sensitive & Chores \\
\hline Variance accounted & $26.71 \%$ & $12.97 \%$ & $16.58 \%$ & $28.80 \%$ & $11.68 \%$ & $23.23 \%$ & $16.31 \%$ & $17.44 \%$ & $16.12 \%$ & $23.56 \%$ \\
\hline Eigenvalue & 2.63 & 1.31 & 15 & 2.85 & 1.41 & 2.22 & 1.73 & 1.87 & 1.76 & 1.96 \\
\hline Do outdoor chores & - & .77 & - & - & .87 & - & -.46 & - & - & .74 \\
\hline P1ay with girls' toys & .63 & - & - & .69 & - & - & .78 & - & 89 & - \\
\hline Play indoors vs, outdoors & 57 & - & - & .70 & - & - & - & - & - & - \\
\hline Play with boys' toys & - & - & .82 & - & - & .72 & - & .78 & - & - \\
\hline Indoor household chores & - & .70 & - & - & 58 & - & - & - & - & .68 \\
\hline Care of younger siblings & - & - & - & - & - & - & - & - & - & 65 \\
\hline Wear bair long & .71 & - & - & .59 & - & - & .68 & - & 84 & - \\
\hline \multicolumn{11}{|l|}{ women coly } \\
\hline Appropriate clothes & .80 & - & - & .76 & - & & & & & \\
\hline Be a "tomboy" & 一 & 一 & .75 & 一 & 42 & & & & & \\
\hline Be "ladylike"/feminine & .79 & - & - & .81 & 一 & & & & & \\
\hline \multicolumn{11}{|l|}{ Men coly } \\
\hline $\begin{array}{l}\text { Engage in boys' } \\
\text { activities }\end{array}$ & & & & & & 83 & - & .88 & - & - \\
\hline Express feetings & & & & & & - & 50 & - & - & .68 \\
\hline $\begin{array}{c}\text { Be "manly" or } \\
\text { "macho" }\end{array}$ & & & & & & .72 & 一 & .62 & - & 一 \\
\hline Scale means $/ S D$ & 2.900 .98 & 1.70 .77 & $26 / 0.90$ & 2.61 .0 & 2.20 .66 & $3.1 / 0.99$ & $1.9 / 0.77$ & $3.4 / 1.1$ & $2.6 / 0.80$ & 1.2 .0 .58 \\
\hline
\end{tabular}

Two scales were created for use in subsequent analyses: social activities (6-item $\alpha=.91)$ and privileges (4-item $\alpha=.70$ ). Means and standard deviations for

Table IV. Factor Loodings for Differential Treatment in Compariscn to Cross-Sex Relatives

\begin{tabular}{|c|c|c|}
\hline & Social activities & Privileges \\
\hline Variance accounted & $41.27 \%$ & $24.57 \%$ \\
\hline $\begin{array}{l}\text { How late you could stay } \\
\text { out on school nights }\end{array}$ & 91 & \\
\hline $\begin{array}{l}\text { How late you could stay out } \\
\text { on weekends }\end{array}$ & .86 & \\
\hline $\begin{array}{l}\text { Where you could go after } \\
\text { school }\end{array}$ & .78 & \\
\hline $\begin{array}{l}\text { Involvement in after-school } \\
\text { activities }\end{array}$ & & .65 \\
\hline When you could start dating & .74 & \\
\hline $\begin{array}{l}\text { With whom you were allowed } \\
\text { to interact }\end{array}$ & .66 & \\
\hline $\begin{array}{l}\text { Being alone with a member } \\
\text { of the other sex }\end{array}$ & .86 & \\
\hline $\begin{array}{l}\text { Getting a license and } \\
\text { learning to drive }\end{array}$ & & .76 \\
\hline Getting a job & & .82 \\
\hline $\begin{array}{l}\text { Having triends of the } \\
\text { other sex }\end{array}$ & & .66 \\
\hline Scale $M / S D$ & 3.21 .0 & 3.10 .78 \\
\hline
\end{tabular}

these two scales are presented at the bottom of Table IV. On these overall scales, young women reported significantly higher levels of restrictions while growing up than did young men for both social activities (women $M=3.5, S D=0.97$; $\operatorname{men} M=2.8, S D=0.92$; $p<.001$ ) and privileges (women $M=3.3, S D=0.69$; men $M=2.9, S D=0.83 ; p<.01)$.

\section{Correlates of Parental Socialization}

To examine associations between gender-related socialization and parental attitudinal and demographic factors, bivariate and multivariate analyses were conducted.

Bivariate correlations are shown in Table $\mathrm{V}$ (young women) and Table VI (young men). The only significant correlations emerging among demographic variables for women (the first five items in Table $\mathrm{V})$ was that for both mothers and fathers, being born outside the United States was linked to more parental Spanish use with each other (but not with other family members). Mothers who held more egalitarian attitudes tended to have younger daughters, be U.S.born, speak English with their spouse, and have higher levels of education. Paternal gender role attitudes were similarly related with fathers' birthplace and educa- 
Table V. Bivariate Correlations Among Study Variables: Female Respondents ${ }^{a}$

\begin{tabular}{|c|c|c|c|c|c|c|c|c|c|c|c|}
\hline & 1 & 2 & 3 & 4 & 5 & 6 & 7 & 8 & 9 & 10 & 11 \\
\hline 1. Age & - & -.04 & .01 & .02 & 00 & $-.22^{k}$ & -.05 & -.05 & -.01 & .09 & .09 \\
\hline 2. Parent U.S. born ${ }^{\hat{b}}$ & -01 & - & $-.70^{\mathrm{kik}}$ & -.11 & 00 & $.23^{k}$ & .00 & $32^{\mathrm{k}}$ & -.06 & -.18 & .06 \\
\hline 3. Spanish use between parents & 01 & $-60^{4 a}$ & - & .14 & -.17 & $-.23^{k}$ & .10 & $-30^{j i}$ & .16 & .05 & -07 \\
\hline 4. Spanish use in family & .02 & -.10 & .14 & - & .10 & -03 & .11 & -.14 & .13 & .02 & 07 \\
\hline 5. Parent education & -05 & .09 & -.09 & .11 & - & $.21^{*}$ & -.10 & .15 & -.09 & .18 & -04 \\
\hline 6. Parent gender attitudes & -.11 & $-35^{\mathrm{had}}$ & .19 & -.06 & $-35^{i x}$ & - & $-.51^{2 k i}$ & -.24 & -.11 & -.13 & -.15 \\
\hline 7. Femininity & -.10 & -.09 & .11 & .15 & -.15 & $-36^{\mathrm{bi} t}$ & - & -.10 & $.38^{2 \pi t}$ & $.21^{*}$ & .14 \\
\hline \&. Tomboy & & & & & & & & - & .05 & -.08 & 09 \\
\hline 9. Chores & -08 & .03 & -.08 & .00 & -01 & 01 & $.27^{k i}$ & & - & .05 & 08 \\
\hline 10. Social activities & .09 & -.12 & .05 & .02 & .15 & .19 & .06 & & $-.0 s$ & - & .02 \\
\hline 11. Privileges & 09 & -.01 & -.07 & .07 & -03 & .18 & .16 & & -.12 & .02 & - \\
\hline
\end{tabular}

Note. $N=97$ (numbers may vary because of missing data on some variables).

"Correlations for mothers are above the diagonal and for fathers below the diagcoal.

Non-U.S. born coded as 0 , U.S. born coded as 1.

${ }^{*} p<.05 .{ }^{* t} p<01 .{ }^{* 1 \mathrm{t}} p<.001$.

tional level. Associations between parental/family characteristics and socialization variables are shown in the upper right and lower left quadrants of the table. Mothers who encouraged femininity in daughters had more traditional gender role attitudes, and mothers who encouraged tomboy behavior tended to be U.S.born and to speak English with their spouse. For fathers, the only significant correlation was between encouragement of femininity and gender role traditionality. Few correlations among the socialization variables emerged: mothers and fathers who encouraged feminine behavior also tended to encourage their daughters to do chores, and mothers who encouraged femininity also placed restrictions on social activities.

Similar patterns emerged among male respondents (Table VI). For both parents, being born outside the United States was linked to more parental Spanish use with each other, and paternal education was related with more use of English with spouse. Mothers who held more egalitarian attitudes tended to speak English with their spouse and to have higher levels of education, and paternal gender role attitudes were similarly related with father's educational level. Again, parental/family characteristics and socialization variables were associated. Mothers who held traditional gender role attitudes were more likely to encourage "manly" behavior in sons. Fathers who encouraged their sons to do chores and limited their sons' freedom regarding social activities tended to have higher levels of education and to hold more egalitarian gender role attitudes. Several unexpected correlations emerged: paternal education was negatively correlated with father's encouragement of sensitivity, and mothers who encouraged sensitive behavior also allowed sons greater freedom regarding social activities compared to female relatives. Finally,

Table VL Bivariate Correlations Among Study Variables: Male Respondents ${ }^{a}$

\begin{tabular}{|c|c|c|c|c|c|c|c|c|c|c|c|}
\hline & 1 & 2 & 3 & 4 & 5 & 6 & 7 & 8 & 9 & 10 & 11 \\
\hline 1. Age & - & .10 & -.13 & .22 & -.10 & -.17 & & -.18 & .01 & -.10 & -06 \\
\hline 2. Parent U.S. born ${ }^{\hat{b}}$ & .17 & - & $-.76^{\mathrm{ink}}$ & -.05 & .14 & .05 & & .10 & .06 & -.09 & .14 \\
\hline 3. Spanish use between parents & -.13 & $-.69^{i d s}$ & - & -.05 & -22 & $-.27^{k}$ & & 01 & .08 & -.01 & -.13 \\
\hline 4. Spanish use in family & .22 & -.06 & -05 & - & .00 & .04 & & -01 & -.01 & -.02 & -02 \\
\hline 5. Parent education & -.09 & .23 & $-.26^{k}$ & .09 & - & $43^{x i a}$ & & -07 & .20 & .15 & -06 \\
\hline 6. Parent gender attitudas & .18 & .12 & .05 & .05 & $-36^{k}$ & - & & $-26^{*}$ & .13 & .16 & -08 \\
\hline 7. Chores & -.07 & .04 & 01 & .23 & $.26^{*}$ & $31^{*}$ & - & & & & \\
\hline 8. Manly & -.01 & .12 & -.12 & .07 & .04 & -.14 & $31^{k}$ & - & .12 & -.06 & -06 \\
\hline 9. Sensitive & .01 & -.15 & -08 & -.09 & $-.29^{k}$ & -.11 & -.05 & .07 & - & $-.26^{k}$ & -.14 \\
\hline 10. Social activities & -.10 & .05 & -.10 & -.02 & $.30^{k}$ & $24^{x}$ & .08 & -05 & -.07 & - & .23 \\
\hline 11. Privileges & -.06 & .09 & -.13 & -.02 & 03 & .09 & -.08 & .00 & -.15 & .23 & - \\
\hline
\end{tabular}

Noce. $N-69$ (numbers may vary because of missing data on scme vaniables).

${ }^{-}$Correlations for mothers are above the diagonal and for fathers below the diagonal.

"Non-U.S. born coded as 0, U.S. born coded as 1.

${ }^{t} p<.05 .{ }^{a} p<.01 .{ }^{a k} p<.001$. 
fathers who encouraged manliness also encouraged their sons to do chores.

Linear regression analyses were conducted to assess the combined and individual associations between parental/family characteristics and socialization behaviors. Because socialization measures differed for women and men, regressions were computed separately by gender. Predictors were entered simultaneously: parental demographic characteristics (birthplace, education), parental language use with each other, family language use, and parental gender role attitudes. For young women, the models for maternal encouragement of femininity and tomboy behavior accounted for a significant amount of variance but the model for chores did not (Table VII). Mothers who were U.S.-born, spoke Spanish with their spouse, and held less egalitarian gender role beliefs tended to be more encouraging of feminine behaviors in their daughters. Although the overall model was significant, there were no individual significant predictors for tomboy behavior. In regressions for fathers, the overall model for encouragement of femininity accounted for a significant amount of variance, with paternal gender role attitudes emerging as a signficant predictor. The overall model for chores was not significant.

In parallel analyses for young men (Table VII), maternal characteristics did not predict socialization for manliness or sensitivity. Similarly, the models for fathers' encouragement of manliness and sensitivity did not account for a significant amount of variance but the model for chores did. Spanish use in the family and paternal egalitarianism emerged as marginally significant predictors of encouragement to do chores. Regression models for limitations in comparison to cross-sex relatives were not significant for either young women or young men.

These results expand on the qualitative findings from Study 1 . The young men and women who participated in Study 2 reported different experiences with household activities, socialization of gender "appropriate" behavior, and freedom to pursue social activities or gain access to privileges. Bivariate and multivariate analyses revealed associations among family characteristics and parental socialization practices. In general, stronger linkages emerged for gender-related socialization by the same-sex parent. Across different analyses, parental gender role attitudes but not demographic variables consistently predicted gender-related socialization by parents.

\section{GENERAL DISCUSSION}

Past research has suggested that considerable variation exists among Latino/a families in how children are socialized regarding gender and sexuality. Some scholars have asserted that aspects of family life related to gender and sexuality may endure because attitudes linked to gender and sexuality are deeply ingrained and imbued with powerful emotions. As a result, "[sexuality and sex roles within a culture tend to remain the last bastion of tradition" (Espin, 1984/1997, p. 93). Other scholars have documented considerable flexibility in such domains as women's contributions to the family economy and marital decision-making (Baca Zinn, 1995) and proposed that

Table VII. Regressions of Parental and Family Characteristics on Gender Socialization Behavior

\begin{tabular}{|c|c|c|c|c|c|c|c|c|c|c|}
\hline & \multicolumn{5}{|c|}{ Women $(n-97)$} & \multicolumn{5}{|c|}{$\operatorname{Men}(n-69)$} \\
\hline & \multicolumn{3}{|c|}{ Mothers } & \multicolumn{2}{|c|}{ Fathers } & \multicolumn{2}{|c|}{ Mothers } & \multicolumn{3}{|c|}{ Fathers } \\
\hline & Femininity & Tomboy & Chores & Femininity & Chores & Manly & Sensitive & Chores & Manly & Sensitive \\
\hline \multicolumn{11}{|l|}{ Variables } \\
\hline $\begin{array}{l}\text { Parent born in } \\
\text { United States }\end{array}$ & $.46^{\mathrm{k}}$ & .21 & .10 & -.01 & -.14 & .17 & .34 & .07 & .14 & -.12 \\
\hline Parental Spanish use & $.40^{\mathrm{ik}}$ & -07 & .19 & -.05 & -.16 & .08 & .37 & .16 & .06 & -.03 \\
\hline Spanish use in family & 05 & -.12 & .12 & .16 &.$\infty$ & .01 & .00 & $.23{ }^{\dagger}$ & .07 & .07 \\
\hline Parental education & 02 & .12 & -.06 & -.04 & -.04 & .04 & .20 & .17 & .08 & $-.26^{\dagger}$ \\
\hline Gender role attitudes & $-49^{j a k}$ & .14 & -.08 & $-36^{n k}$ & .07 & $-.27^{\dagger}$ & .08 & $.24^{\dagger}$ & -.17 & -.01 \\
\hline \multicolumn{11}{|l|}{ Model statistics } \\
\hline Multiple $R^{2}$ & $32^{6 k t}$ & $.16^{a k}$ & .05 & $.15^{*}$ & .02 & .08 & .09 & $.18^{t}$ & 04 & .10 \\
\hline$F$ & 7.74 & 3.26 & 1.01 & 3.04 & 0.27 & 1.10 & 1.23 & 2.63 & 0.51 & 1.30 \\
\hline
\end{tabular}

Note. Figures are standardized regression coetncients $(\beta)$. Numbers may vary because of missing data on some variables.

${ }^{t} p<.05 .{ }^{k t} p<.01 .{ }^{\text {is }} p<.001 .{ }^{\dagger} p<07$. 
traditional views of Latino/a families do not fully capture the range of variation (e.g., Amaro, 1988; Singer et al., 1990). In an attempt to expand the meager literature on how Latino/a parents socialize their children, we examined gender socialization practices retrospectively reported by Latino/a adults who participated in these two studies.

Our first goal was to examine parenting practices linked to gender-related socialization in Latino/a families. The findings support the view that Latinas and Latinos experience differential gender socialization while growing up. When asked about limitations placed on them as compared to cross-sex siblings or relatives while growing up, participants reported the greatest differential treatment on items regarding curfews and interacting with members of the other sex. These findings are consistent with prior reports that Latina adolescents experience stricter rules about dating than do their male peers (e.g., Hovell et al., 1994; Villaruel, 1998). In addition, gender differentiation was seen in areas not obviously linked to sexuality, such as involvement in after-school activities and the age at which respondents were allowed to get a license or a job. In all cases, female respondents reported more limits than did male respondents. Because the young men in our sample agreed that they were granted more freedom than their sisters or other female relatives, it is unlikely that the findings reflect young women's perceptions rather than actual differences in parental behavior. Instead, it appears that many Latino/a parents in the United States observe a traditional division of the world into gendered spheres (Rossi, 1985; Williams \& Best, 1994) and attempt to protect daughters by keeping them close to home. Future researchers should explore parents' explanations for their behavior, and elucidate the extent to which parenting practices reflect concern about potential sexual involvement as opposed to physical safety or other factors.

We also found that mothers do more direct gender socialization of daughters and fathers do more socialization of sons. For example, young women rated their mothers higher than fathers on items that assessed parental encouragement to wear gender-appropriate clothes, be ladylike, and play with girls' toys. In contrast, young men rated their fathers higher than mothers on items that assessed encouragement to be involved in masculine activities and act "manly or macho," and lower on items that assessed encouragement to express their feelings. These results are consistent with those reported in studies of non-Latino/a families (see McHale, Crouter, \& Whiteman, 2003, for review). For instance, a recent meta-analysis (Leaper, Anderson, \& Sanders, 1998) revealed that mothers and fathers tend to talk differently to their children depending on the child's gender. Other studies have shown that mothers typically spend more time and know more about their daughters' activities, whereas fathers spend more time with, and know more about the activities of their sons (Harris \& Morgan, 1991; McHale, Crouter, \& Tucker, 1999). Together with the results of the current study, this body of literature suggests that the process of gender-typing is similar across different ethnic groups; however, the extent to which the content of parental messages regarding what it means to be a women or a man varies by ethnicity remains to be explored. The current findings provide insight into how Latino/a parents organize the task of inculcating gender-related behaviors in their children, and suggest avenues for future research on family practices related to socialization of sons and daughters.

The second goal of the study was to examine linkages between parental/family characteristics and gender socialization practices. For these analyses, scales were created to measure gender-specific factors related to gender role socialization and differential treatment. Several factors were quite robust and had good reliability, which suggests that they assessed meaningful dimensions of experience; others had only two or three items, and thus were less satisfactory. Unexpectedly, factor analyses of the same items completed by male and female respondents revealed that three factors emerged for the same-sex parent but only two factors emerged for the cross-sex parent (e.g., for young women, factors that tapped into femininity and chores emerged for both parents, but an additional tomboy factor emerged for mothers). It may be that interactions between children and parents of the same sex are more nuanced than those in mixed-sex dyads, a possibility that may be related to the earlier finding that the same-sex parent engages in more gender-related socialization.

Analyses of correlates of gender socialization practices revealed that, in general, demographic characteristics (including parental birthplace, education, and language use) did not directly predict gender socialization behaviors. Instead, gender role attitudes (which did tend to be associated with these demographic characteristics) emerged as the most consistent 
predictor of parental socialization. For daughters, both maternal and paternal gender role traditionality were linked to the encouragement of stereotypically feminine behavior; for sons, maternal traditionality was linked to encouragement of stereotypically masculine behavior and paternal egalitarianism and use of English with spouse was (marginally) related to encouragement of chores. Because prior research on gender socialization has not focused on correlates of socialization practices, it is impossible to compare these results to those from other studies. However, these findings suggest that demographic variables may be important to the extent that they affect parental gender role beliefs, rather than in and of themselves. Therefore, future researchers should directly assess culturally relevant variables (e.g., values and beliefs) as well as demographic variables, and examine how both sets of variables operate on family gender socialization.

\section{Limitations and Future Directions}

In closing, we identify key study limitations and suggest directions for future research on this topic. One set of limitations involves sample issues. The samples for the two studies differed in ways that may have affected the study outcomes. Most importantly, Study 1 included only women; thus, the structured measures created for Study 2 may not have reflected socialization experiences unique to men. The small sample size in Study 1 may also have resulted in measures that did not reflect the full range of women's socialization experiences. The two study samples were also demographically different (e.g., level of parental education), and neither sample is representative of the general population of Latinos/as. By design, Study 1 targeted highly acculturated women and involved an opportunity sample, whereas Study 2 targeted college and university students through direct mailings. Given that just over one-third of U.S. Latino/a high school graduates currently attend college (Wilds \& Wilson, 1998), Study 2 participants are likely to be more acculturated and of higher socioeconomic status than the general Latino/a population. However, the fact that differential gender-related socialization was so pervasive even in this sample suggests that the study results would be even stronger in a more representative sample. To address these limitations, future researchers should examine socialization experiences in samples that include both male and female respon- dents who represent the diversity of the Latino/a population in the United States.

A second limitation is the retrospective study design, which involved asking adults to recall experiences from their childhood and adolescence. It has been argued that such retrospective approaches are valid ways of assessing family of origin experiences that are linked to adult functioning (e.g., Melchert \& Sayger, 1998), and other researchers have employed similar designs to assess characteristics of Latino/ a families (e.g., López \& Hamilton, 1997). However, recall biases and reevaluation of past experiences may have affected the results in unknown ways. Moreover, it should be noted that parental gender role attitudes were assessed indirectly (by having respondents rate their parents), rather than by obtaining reports directly from parents. To address these design limitations, future researchers should assess gender socialization patterns in representative samples of Latino/a children and adolescents. Ideally, such research would explore not only the perspectives of children but also their parents' values and beliefs about gender role socialization.

As the population of the United States becomes increasingly diverse, there is a critical need to learn how families from different groups socialize their children. In recent years, scholars have decried the lack of high-quality research on how ethnically diverse families raise their children and pointed out the limited knowledge that can be gained from simple ethnic group comparisons (e.g., McLoyd et al., 2000). To gain accurate and usable information to inform scholarship and practice, researchers need to dedicate the same attention to understanding ethnically diverse children and adolescents that they have invested in understanding developmental processes among majority populations in the past. In an effort to contribute to this goal, the current study provides novel information on how Latino/a parents socialize their sons and daughters, builds on the scant body of research on this topic, and offers directions for future research.

\section{ACKNOWLEDGMENTS}

This research was funded by grants to Marcela Raffaelli from the National Institutes of Health (RO3-MH57650) and by the University of Nebraska Research Council. Research assistance was provided by Jennifer Crispo, Jennifer Haase, Stephanie Hewitt, Sarah Kepple, Lynn Marcus, Nicole Miller, Tammy Pfeifer, Katie Pickett, Julie Siepker, Kathryn Wilke, and Byron Zamboanga. 


\section{REFERENCES}

Amaro, H. (1988). Women in the Mexican-American community: Religion, culture, and reproductive attitudes and experiences. Journal of Community Psychology, 16, 6-20.

Arnett, J. J. (2001). Adolescence and emerging adulthood. Upper Saddle River, NJ: Prentice Hall.

Baca Zinn, M. (1995). Social science theorizing for Latino families in the age of diversity. In R. E. Zambrana (Ed.), Understanding Latino families: Scholarship, policy, and practice (pp. 177-189). Thousand Oaks, CA: Sage.

Comas-Diaz, L. (1987). Feminist therapy with Hispanic/Latina women: Myth or reality? Women and Therapy, 6(4), 39-61.

Darabi, K. F., \& Ascencio, M. (1987). Sexual activity and childbearing among young Hispanics in the U.S. SIECUS Reports, 15, 6-8.

Day, J. C. (1996). Population projections of the United States by age, sex, race, and Hispanic origin: 1995 to 2050 (U.S. Bureau of the Census, Current Population Reports, P25-1130). Washington, DC: U.S. Government Printing Office.

Espin, O. M. (1984/1997). Cultural and historical influences on sexuality in Hispanic/Latin women: Implications for psychotherapy. In O. M. Espin (Ed.), Latina realities: Essays on healing, migration, and sexuality (pp. 83-96). Boulder, CO: Westview.

Flores, E., Eyre, S., \& Millstein, S. G. (1998). Sociocultural beliefs related to sex among Mexican American adolescents. Hispanic Journal of Behavioral Sciences, 20, 60-82.

Harris, K. M., \& Morgan, S. P. (1991). Fathers, sons, and daughters: Differential parental involvement in parenting. Journal of Marriage and the Family, 53, 531-544.

Hill, J. P., \& Lynch, M. E. (1983). The intensification of gender-related role expectations during early adolescence. In J. Brooks-Gunn \& A. C. Peterson (Eds.), Girls at puberty: Biological, psychological, and social perspectives (pp. 201-229). New York: Plenum.

Hovell, M., Sipan, C., Blumberg, E., Atkins, C., Hofstetter, C. R., \& Kreitner, S. (1994). Family influences on Latino and Anglo adolescents' sexual behavior. Journal of Marriage and the Family, 56, 973-986.

Huston, A. C. (1983). Sex-typing. In E. M. Hetherington (Ed.), Handbook of child psychology: Vol. 4. Socialization, personality, and social development (4th ed., pp. 1-101). New York: Wiley.

Huston, A. C., \& Alvarez, M. (1990). The socialization context of gender role development in early adolescence. In R. Montemayor, G. R. Adams, \& T. P. Gullotta (Eds.), From childhood to adolescence: A transitional period (pp. 156-179). Newbury Park, CA: Sage.

Leaper, C. (1993). USCS Attitudes Toward Gender Scale. Unpublished manuscript, University of California at Santa Cruz (cam@cats.ucsc. edu).

Leaper, C., Anderson, K. J., \& Sanders, P. (1998). Moderators of gender effects on parents' talk to their children: A metaanalysis. Developmental Psychology, 34, 3-27.

López, L. C., \& Hamilton, M. (1997). Comparison of the role of Mexican-American and Euro-American family members in the socialization of children. Psychological Reports, 80, 283-288.

Lytton, H., \& Romney, D. M. (1991). Parents' differential socialization of boys and girls: A meta-analysis. Psychological Bulletin, 109, 267296.

Marin, B. V., \& Gomez, C. A. (1997). Latino culture and sex: Implications for HIV prevention. In J. Garcia \& M. Zea (Eds.), Psychological interventions and research with Latino populations (pp. 73-93). Boston: Allyn \& Bacon.

Marin, G., Sabogal, F., Marin, B. V., Otero-Sabogal, R., \& Perez-Stable, E. J. (1987). Development of a short acculturation scale for Hispanics. Hispanic Journal of Behavioral Sciences, 9, 183-205.
McDade, K. (1995). How we parent: Race and ethnic differences. In C. K. Jacobson, (Ed.), American families: Issues in race and ethnicity (pp. 283-300). New York: Garland.

McHale, S. M., Crouter, A. C., \& Tucker, C. J. (1999). Family context and gender role socialization in middle childhood: Comparing girls to boys and sisters to brothers. Child Development, 70, 990-1004.

McHale, S. M., Crouter, A. C., \& Whiteman, S. D. (2003). Topic review: The family contexts of gender development in childhood and adolescence. Social Development, 12, 125-146.

McLoyd, V. C., Cauce, A. M., Takeuchi, D., \& Wilson, L. (2000). Marital processes and parental socialization in families of color: A decade review of research. Journal of Marriage and the Family, 62, 10701093.

Melchert, T. P., \& Sayger, T. V. (1998). The development of an instrument for measuring memories of family of origin characteristics. Educational and Psychological Measurement, 58, 99-118.

Parke, R. D., \& Buriel, R. (1998). Socialization in the family: Ethnic and ecological perspectives. In N. Eisenberg (Ed.), Handbook of child psychology: Vol. 3. Social, emotional, and personality development (5th ed., pp. 463-552). New York: Wiley.

Raffaelli, M., \& Ontai, L. L. (2001). "She's sixteen years old and there's boys calling over to the house": An exploratory study of sexual socialization in Latino families. Culture, Health, and Sexuality, 3, 295310 .

Raffaelli, M., \& Suarez-al-Adam, M. (1998). Reconsidering the HIV/AIDS prevention needs of Latino women in the United States. In N. L. Roth \& L. K. Fuller (Eds.), Women and AIDS: Negotiating safer practices, care, and representation (pp. 7-41). New York: Haworth.

Reid, P. T., Haritos, C., Kelly, E., \& Holland, N. E. (1995). Socialization of girls: Issues of ethnicity in gender development. In H. Landrine (Ed.), Bringing cultural diversity to feminist psychology: Theory, research, and practice (pp. 93-111). Washington, DC: American Psychological Association.

Rossi, A. (1985). Gender and the life course. New York: Aldine.

Ruble, D. M., \& Martin, C. L. (1998). Gender development. In N. Eisenberg (Ed.), Handbook of child psychology: Vol. 3. Social, emotional, and personality development (5th ed., pp. 933-1016). New York: Wiley.

Singer, M., Flores, C., Davison, L., Burke, G., Castillo, Z., Scanlon, K., et al. (1990). SIDA: The economic, social, and cultural context of AIDS among Latinos. Medical Anthropology Quarterly, 4, 72-114.

Taylor, J. M. (1996). Cultural stories: Latina and Portuguese daughters and mothers. In B. J. R. Leadbeater \& N. Way (Eds.), Urban girls: Resisting stereotypes, creating identities (pp. 117-131). New York: New York University Press.

U.S. Department of Health and Human Services. (2001). Mental health: Culture, race, and ethnicity-Supplement to mental health: A report of the Surgeon General. Rockville, MD: Author.

Valenzuela, A. (1993). Liberal gender role attitudes and academic achievement among Mexican-origin adolescents in two Houston inner-city schools. Hispanic Journal of Behavioral Sciences, 15, 310-323.

Villaruel, A. M. (1998). Cultural influences on the sexual attitudes, beliefs, and norms of young Latina adolescents. Journal of the Society of Pediatric Nurses, 3, 69-79.

Wilds, D. J., \& Wilson, R. (1998). Minorities in higher education 19971998. Washington, DC: American Council on Education.

Williams, J. E., \& Best, D. L. (1994). Cross-cultural views of women and men. In W. J. Lonner \& R. S. Malpass (Eds.), Psychology and culture (pp. 191-196). Boston: Allyn \& Bacon. 